\title{
DAS TENSÕES ENTRE HISTÓRIA E SOCIOLOGIA NA PRIMEIRA METADE DO SÉCULO XX E SUAS RELAÇÕES COM O TEXTO DE A ARQUEOLOGIA DO SABER
}

\section{SUR LES TENSIONS ENTRE HISTOIRE ET SOCIOLOGIE DANS LA PREMIĖRE MOITIÉ DU XX E SIĖCLE ET SES RELATIONS AVEC LE TEXTE DE L'ARCHÉOLOGIE DU SAVOIR}

ESTÊVÃO DE CARVALHO FREIXO*

\section{RESUMO}

A despeito da clara indicação que A Arqueologia do Saber faz de seu compromisso com o trabalho de análise histórica, os discursivistas de hoje continuam se perguntando o que essa obra tem a lhes dizer sobre o discurso, enquanto deixam na sombra relações fundamentais que serviram de impulso ao seu desenvolvimento. Para examiná-las, retomamos neste artigo algumas polemizações entre história e sociologia que, no início do século $X X$, convocaram a história a uma revisão de seus procedimentos, a fim de que pudesse se aproximar do que se pretendia à época como "ciência social positiva". Nessa direção, analisamos as relações de intertextualidade existentes entre a obra de Foucault e alguns textos de importância fundacional para a historiografia francesa do século XX.

PALAVRAS-CHAVE: História. Sociologia. AArqueologia do Saber.

\section{RÉSUMÉ}

Malgré l'indication claire que l'Archéologie du Savoir fait de son engagement dans le travail d'analyse historique, les discursivistes d'aujourd'hui continuent à se demander ce que cet ouvrage a à leur dire sur le discours, en laissant dans l'ombre les relations fondamentales qui ont servi d'impulsion à son développement. Pour les examiner, nous revenons dans cet article sur quelques controverses entre histoire et sociologie qui, au début du XXe siècle, appelaient I'histoire pour une révision de ses procédures, afin qu'elle puisse aborder ce qu'on entendait à l'époque comme "sciences sociales» positif. Dans ce sens, nous analysons les relations intertextuelles existant entre l'œuvre de Foucault et certains textes d'importance fondamentale pour l'historiographie française du XXe siècle

MOTS-CLÉS: Histoire. Sociologie. l'Archéologie du Savoir

\footnotetext{
* Mestrando em linguística - Programa de Pós-graduação em Letras - Faculdade de Letras - UERJ Universidade do Estado do Rio de Janeiro - UERJ/PPGL. E-mail: estevaofreixo@gmail.com.br
} 
Introdução

Eis como, em A Arqueologia do Saber, Foucault dá início ao primeiro capítulo que integra, junto dos demais, a espessura desta obra tão prestigiada entre os pesquisadores que exploram o campo das ciências humanas:

\begin{abstract}
O emprego dos conceitos de descontinuidade, de ruptura, de limiar, de limite, de série, de transformação, coloca, a qualquer análise histórica, não somente questões de procedimento, mas também problemas teóricos. São estes os problemas que vão ser aqui estudados (as questões de procedimento serão consideradas no curso das próximas pesquisas empíricas, se eu tiver, pelo menos, a oportunidade, o desejo e a coragem de empreendê-las). (FOUCAULT, 2008, p. 23)
\end{abstract}

A despeito dessa clara indicação que o livro faz de seu compromisso com o trabalho de análise histórica, assim como do longo introito que a precede e que alinha passo a passo as transformações mais importantes ocorridas no domínio da historiografia francesa durante o século $X X$, os analistas do discurso que hoje têm suas pesquisas orientadas pelo campo das ciências da linguagem se perguntam frequentemente 0 que afinal têm a lhes dizer sobre o discurso os adornos que cobrem as páginas deste belo livro, enquanto deixam na sombra essas relações fundamentais que serviram de impulso ao desenvolvimento da obra. Passam por essa indicação inicial, como se não precisassem se haver em primeiro com o campo da história para estarem aptos a acompanhar o que o livro apresenta; ou agem como se não pudessem fazê-lo, como se não lhes fosse permitido atravessar as fronteiras do terreno teórico no interior do qual estão felizmente autorizados a elaborar os materiais que ali se encontram - desses sim sentindo-se legítimos titulares.

Condicionados a trabalharem no espaço recortado por forças institucionais que ao longo dos últimos séculos Ihes atribuíram tarefas e objetivos particulares, perguntas e preocupações que lhes são exclusivas, acostumaram-se esses discursivistas a tomar o texto sobre o qual aqui nos inclinamos - o célebre arquitexto de Michel Foucault como ponto de partida para o desenvolvimento de suas elaborações sobre o discurso ou como fonte teórica para o exercício de suas análises.

Ora, a questão que se coloca é que, tendo sido esta obra produzida na forma de um comentário cuja finalidade é a de se afetar um debate que há décadas se desdobrava no campo da história - e também no espaço de interseção entre ela e alguns domínios vizinhos -, não nos parece possível assumir que uma aproximação convenientemente preparada do texto possa dispensar o esforço de nos inteirarmos minimamente a respeito das tensões sob as quais esse diálogo foi durante longo tempo desenvolvido até que fosse possível a materialização dessa obra.

Com o propósito de enfrentar esse obstinado problema, e bem cientes das imposições que a cediça setorialização do saber antepõe à realização de nossa empresa, retomaremos neste trabalho algumas polemizações entre história e sociologia que tiveram lugar na França do fim do século XIX e início do XX, provocando a história a uma revisão de seus procedimentos, a fim de que pudesse aproximar-se de um trabalho em maior conformidade com o que os herdeiros das tradições sociológicas saint-simoniana e comptiana compreendiam à época como "ciência positiva". 
Do ponto de vista procedimental, indicaremos a presença de tais controvérsias em alguns textos fundacionais que, segundo supomos, serviram como condição de possibilidade à produção do texto A Arqueologia do Saber de Michel Foucault. Estabelecendo, pois, relações intertextuais com trabalhos anteriores cuja existência prévia tornou possível seu aparecimento ulterior, a referida obra adquire, além de seu lugar fundador, o estatuto de texto-comentário.

As condições de possibilidade aqui referidas serão, portanto, consideradas como dadas em um espaço intertextual no interior do qual alguns textos precedentes tornaram possível a emergência da Arqueologia do Saber. Queremos assim supor que, em consequência de seu lugar segundo em relação aos textos anteriores, a obra aqui estudada deve parte importante de sua constituição ao diálogo que mantém com os textos que retoma.

Nesse sentido, podemos dizer que os textos precedentes, que podem ser também situados como intertextos, dada sua posição primeira no espaço intertextual (KOCH, 2017), servem como condição de possibilidade aos textos posteriores que os comentam. Sendo assim, talvez nos seja pertinente ajustar a condição de possibilidade antes referida, reduzindo seu alcance ao que tomaremos estritamente como condição (textual) de possibilidade - categoria que, para esta ocasião, admitiremos com ponto de apoio em nosso percurso de análise.

Em nossa seleção de textos, trabalharemos com o artigo do sociólogo François Simiand, Méthode historique et science sociale, de 1903, produzido em resposta ao livro La méthode historique appliquée aux sciences sociales, de Charles Seignobos, que a seu tempo era autoridade reconhecida no terreno da historiografia então tradicional.

Aos problemas levantados por Simiand acerca dos métodos utilizados pelos historiadores de sua época, acrescentaremos os desdobramentos de um debate realizado na Société Française de Philosophie após uma conferência conduzida por Seignobos, quando Durkheim e outros interlocutores confrontaram o palestrante num diálogo registrado nos boletins desta casa como Débat sur l'explication en histoire et en sociologie.

Finalmente, encadearemos com os anteriores o texto Histoire et Sociologie, publicação cronologicamente mais próxima da obra de Foucault, na qual o historiador Fernand Braudel comenta a antiga controvérsia entre estes dois campos e reflete sobre os desafios de entendimento que à sua época se atualizavam. Nesse momento, o cenário para os historiadores já era certamente de grande renovação.

\section{Entre a história e a ciência positiva: o problema do método}

Em princípios do século $X X$, um grande debate instaurou-se no âmbito das ciências humanas acerca do método utilizado pelos historiadores franceses da chamada Escola Metódica. Com as conquistas alcançadas pelas ciências naturais, o atendimento a certas exigências metodológicas havia se tornado um critério indispensável de validação do conhecimento, e, segundo se pensava na esfera sociológica, a história não 


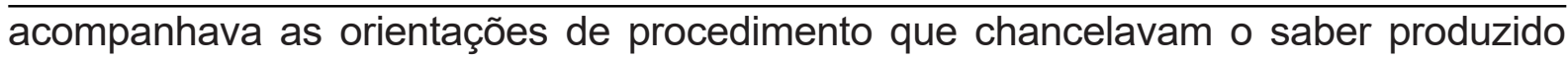
pelas ciências ditas positivas.

A esse respeito, parece razoável dizer que François Simiand foi o cientista que, nesse momento, contribuiu de forma mais decisiva para a produção de um giro na ciência histórica que viria a marcar definitivamente a orientação dos trabalhos produzidos neste campo.

Em resposta à publicação de La méthode historique appliquée aux sciences sociales - obra em que Charles Seignobos apresenta uma visão subjetivista da história, Simiand produziu um célebre artigo por meio do qual realizou uma exposição habilidosa das inconsistências presentes no trabalho de Seignobos, demonstrando que o caminho proposto pelo historiador mostrava-se insuficiente para se alcançar o grau desejável de rigor que permitiria à história tornar-se uma legítima ciência positiva. Em seu trabalho, François Simiand expunha que o método histórico correspondia a um processo de conhecimento experimental indireto, o que implica dizer que o saber alcançado era, neste caso, obtido por intermediação de outro espírito que não o do próprio investigador.

Com efeito, Seignobos defendia esse procedimento, e o justificava sustentando que a história nada tinha como material de trabalho além do reflexo de acontecimentos vistos e relatados por aqueles que os haviam presenciado. Por esta razão, os próprios elementos de sua ciência faltavam aos historiadores para um exercício de observação direta. Era forçoso, portanto, que os investigadores lidassem no ofício da história com materiais de segunda mão. E, como só se podia conhecer os fatos por quem os havia antes experimentado, inclinavam-se estes cientistas a atribuir grande relevo aos motivos expressos pelas testemunhas e pelos agentes diretamente envolvidos com os fatos analisados.

As explicações produzidas por estes espectadores diretos eram então estudadas mediante o recurso aos meios documentais, que retinham os acontecimentos relatados no interior de seu esquema textual. Mas esses registros documentais não eram produzidos segundo métodos especializados cujo propósito fosse o de atender aos fins da ciência. Por essa razão, Simiand sustentava que os documentos, ainda que permitissem a observação indireta de certa categoria de fenômenos, não deveriam ser reconhecidos como instrumentos propriamente científicos. A esse respeito, lembramos que o modelo de ciência perseguido pelos sociólogos era neste momento aquele que havia se desenvolvido com reconhecido êxito no âmbito das ciências da natureza, pelo que se buscava uma concepção metodológica que fosse análoga ao ponto de vista ali adotado.

\section{O domínio das objetividades nas ciências sociais}

Como bem se sabe, a ciência natural dos últimos séculos alinhou-se ao objetivismo positivista, buscando esquivar-se da nuviosidade e da indistinção que o pensamento iluminista do século XVIII havia denunciado a respeito da metafísica medieval. Em conformidade com esta orientação, Simiand problematizou a posição de

Revista História em Reflexão, Vol. 15, N. 29 | jan. a jun. de 2021 
Seignobos, por haver este sustentado que o fato social é um fenômeno psicológico, e por ser psicológico é também subjetivo (SIMIAND, 2003). Com efeito, não era possível ao sociólogo admitir a identidade resultante dessa premissa, face à ameaça que representava ao projeto de constituição de uma ciência social positiva. A declaração do historiador francês não se alinhava aos critérios de produção científica perseguidos por Simiand, porque não atendia ao imperativo de se proceder à investigação dos fenômenos tomando por base sua existência no interior de um domínio objetivo.

Para levar adiante o debate, François Simiand tomou para si a providência de melhor precisar as diferenças entre o que se compreendia como fenômeno objetivo e subjetivo, pelo que retomou a noção de objeto, sustentando-a a partir do que acreditava ser o seu uso legítimo no trabalho de investigação científica. Nessa direção, adotou a posição de um empirismo relativista, dado que negava a substancialidade como propriedade da matéria. Dizia o autor que "o objeto, a coisa do mundo que chamamos de exterior, não é, do ponto de vista do conhecimento empírico, mais do que um simples conjunto de sensações constituído no todo através da abstração" (SIMIAND, 2003, p. 168, tradução nossa).

Desse ponto de vista, a realidade psicológica não se encontrava em oposição à objetividade do mundo, ao contrário do que implicitamente se lia nas palavras de Seignobos, quando reduzia o psicológico ao subjetivo. Isto porque, neste caso, a experiência estava na base da formação dos objetos, que se constituíam mediante certo tratamento daquilo que se experimentava.

Além disso, Simiand admitia que a experiência, em sua integralidade, era determinada tanto pelos aspectos subjetivos da sensação, quanto por fatores que se impunham a nossa existência individual a partir do exterior. Tomando em conta essa natureza dual da experiência, defendia como tarefa da ciência positiva o trabalho de "extrair o objetivo do subjetivo para estudá-lo" (SIMIAND, 2003, p. 168, tradução nossa).

Os fenômenos sociais - e sobretudo estes - eram igualmente admitidos pelos sociólogos como abstrações, tendo em vista serem o resultado da extração de aspectos objetivos de uma dada experiência coletiva. Mas não o eram mais nem menos que os fenômenos orgânicos, químicos, físicos, etc. O sociólogo tinha, portanto, o mesmo direito que os cientistas naturais de se apoiar em tais abstrações para perseguir resultados no interior de seu próprio campo de conhecimento.

Adicionalmente, a concepção de objetividade científica proposta por Simiand se definia pela autonomia dos fenômenos examinados em relação à espontaneidade humana. Isto significava dizer que, não estando sujeitos a nossa vontade, mas tendo nos sido impostos desde o exterior, os fenômenos possuiriam um caráter objetivo. Em última instância, o que importava dizer é que as coisas que em nós procedem da sociedade têm, de acordo com este significado, uma natureza objetiva.

Por todas essas razões, postulava Simiand que os fenômenos sociais são realidade no mesmo sentido em que os elementos materiais são uma realidade para 
o conhecimento positivo, assim como são objetos no mesmo sentido em que o são as coisas do mundo chamado exterior.

\section{Causa, lei e regularidade}

Mesmo admitindo a existência dos fenômenos sociais e a particularidade de sua natureza, a aposta dos historiadores franceses no final do século XIX era de que sua origem não era estranha à ação dos indivíduos. Isto porque, embora nós os encontrássemos já prontos e em funcionamento, tais fenômenos poderiam ter seu começo remontado a um ponto distante no passado quando os indivíduos teriam entre si estabelecido contratos ou convenções que valeriam às construções do social como marcos fundadores.

Consequentemente, a razão da existência dos fenômenos sociais devia ser encontrada no ânimo dos indivíduos. E, nesse sentido, Seignobos (1908) defendia que os motivos interiores dos agentes eram causas imediatamente disponíveis aos historiadores, já que nas fontes documentais registravam-se os atos conscientes que haveriam orientado a realização de tais fenômenos. Precisamente nesse aspecto, apoiava-se em premissas subjetivistas com as quais organizava e orientava seu trabalho metodológico, de modo a aproximá-lo ao domínio da psicologia.

Em contrapartida, Durkheim e Simiand se opunham francamente a tais argumentos. O primeiro intervinha no sentido de romper com as identidades que Seignobos supunha entre consciente e conhecido ou inconsciente e desconhecido. Para Durkheim, o consciente era igualmente cheio de obscuridades, e, dessa forma, dificuldades incontornáveis se colocavam ao investigador em sua tentativa de conhecer as motivações que levavam os agentes a provocarem os eventos. Mais que isso, assumia o autor que qualquer relação causal na esfera psíquica era da ordem do inconsciente. E ainda que um fato psíquico pudesse ser alcançado pela introspecção, a mesma coisa não se garantia em relação a sua causa inconsciente. Logo, se os agentes não tinham acesso aos elementos fundadores de sua experiência, como se poderia confiar em suas palavras para se determinar o fundamento dos fatos que eles desencadeavam por meio de suas ações? Além disso, o estudo dos acontecimentos sociais a partir do exame da consciência de testemunhas e agentes mostrava-se especialmente desafiador. Se as causas dos fatos psíquicos não se apresentavam claramente aos indivíduos, tanto mais inacessíveis eram as determinações inconscientes dos fenômenos coletivos (DURKHEIM et al., 1908, p. 4-5).

François Simiand, à sua vez, atuou estrategicamente sobre um nível mais essencial, realizando uma revisão do próprio conceito de causa, sobre o qual as ciências invariavelmente necessitam apoiar-se para formar seus sistemas explicativos. Distinguiu-se da posição dos historiadores tradicionais da seguinte maneira. Enquanto estes destacavam que os fenômenos por eles estudados eram promovidos por agentes conscientes e racionais, cujas motivações deveriam ser tomadas como causa dos acontecimentos históricos, o autor argumentava que, no paradigmal domínio da 
natureza, a noção de agente, como entidade substancial ativa, havia sido rechaçada e substituída pelo uso de metáforas, como "o calor", "a eletricidade", etc. - abstrações que serviam como indicações objetivas de uma dada categoria de fenômenos. Fixavase o cientista, portanto, numa noção de causa cujo sentido cingia-se ao estritamente positivo.

Outra questão que esse tempo também atravessava a querela entre historiadores e sociólogos diz respeito à possibilidade ou não de se atribuir uma causa a eventos que ocorrem uma única vez, já que a impossibilidade de reprodução de um fenômeno torna difícil a identificação de suas determinações. No que a isso concerne, Seignobos se posicionava de modo afirmativo. Durkheim, a seu turno, ponderava que as leis que regulam os fenômenos não são definidas pela frequência em que suas ocorrências se manifestam, sendo apenas necessário que a relação estabelecida entre dois elementos reciprocamente implicados seja de natureza a se reproduzir para que uma norma venha a se configurar. Desse ângulo, encontrar uma causa corresponderia a identificar um tipo de relação cuja ocorrência tende a se repetir, o que, ao mesmo tempo, faria supor a existência de uma lei por meio da qual tal relação seguidamente se atualiza.

Outrossim, separava o sociólogo dois objetos de estudo marcadamente distintos, os acontecimentos históricos e as funções sociais permanentes. No exame dos acontecimentos, encontrava-se uma massa indefinida de fatos a respeito da qual dificilmente se poderia introduzir uma ordem científica. No domínio das regularidades, por outro lado, estavam as funções, as instituições, os modos de pensar ou agir fixos e organizados, sobre cujos funcionamentos se poderia efetivamente lançar alguma luz.

François Simiand, de sua parte, compreendia que as ocorrências singulares, únicas de sua espécie, como não são explicadas por uma relação constante, não exigem a presença de um antecedente invariável, e, assim, não podem estar vinculadas a um princípio causal que as determine. Por essa razão, o trabalho de identificação das causas deveria contar com a regularidade dos fenômenos. Por fim, defendia a existência de um vínculo necessário entre a atribuição da causa de um fenômeno e o estabelecimento de uma lei pela qual o seu funcionamento é ordenado, já que a causa só poderia ser encontrada em ocorrências de caráter regular, e a regularidade, à sua vez, importava a existência de leis segundo as quais os fatos se organizavam.

Dessa forma, em resposta à restrição que os historiadores se impunham no sentido de dirigir seus próprios interesses à observação de fenômenos que aconteciam uma única vez, Simiand lhes prescrevia que, ao contrário, considerassem os fatos que ocorrem segundo uma frequência definida, renunciando aos fenômenos acidentais e se dedicando aos que se repetem. Este seria o caminho pelo qual o estudo dos fatos humanos poderia constituir-se em autêntica ciência positiva.

Com efeito, contingências e regularidades coexistiam no pano de fundo da história. Todavia, em lugar de se pôr em evidência a ordem sucessiva das contingências, o trabalho essencial deveria ser o de se extrair as relações estáveis e definidas que podiam aparecer entre os fenômenos. 
Todas essas interferências da orientação sociológica no campo da história pretendiam indicar que o estudo voltado às relações objetivas e constantes do mundo social em lugar do exame mediato das motivações individuais tornava possível que se chegasse aos fatos estudados pela via direta de uma análise da dimensão positiva dos fenômenos considerados, tornando dispensável, portanto, o recurso ao testemunho de terceiros.

\section{Fernand Braudel: os fenômenos regulares na dinâmica do tempo}

Num quadro geral, história e sociologia dividiam seu interesse pelo passado, voltando-se a primeira para o que ali se podia reter de singular - os acontecimentos que se davam uma única vez -, enquanto as repetições, as relações fixas e regulares formavam o campo para o qual os sociólogos dirigiam sua atenção. Essa diferença entre os campos motivava uma atitude de protesto da sociologia contra uma história que fosse restrita aos eventos singulares, pelo que os sociólogos incitavam a comunidade dos historiadores a buscar uma ciência histórica que tivesse um caráter não eventual. $E$, nessas circunstâncias, tornava-se premente uma intensa aproximação com as demais ciências do social, posto que nessas outras regiões, onde os fenômenos de ocorrência regular ocupavam um lugar central, encontravam-se já disponíveis alguns recursos para a construção de um novo projeto de ciência, como pretendiam os sociólogos.

Esta imperiosa e inadiável associação entre as ciências humanas tomou corpo ao longo do século XX primeiramente com a inauguração da Revue de synthèse historique de Henri Berr, em 1900, e, em seguida, com o movimento inaugurado por Lucien Febvre e Marc Bloch, quando da fundação do periódico Annales d'histoire économique et sociale, em 1929. A partir daí, a história expandiu sua compreensão e suas formas de proceder em relação ao estudo do passado, integrando entre os fenômenos de seu interesse tanto os fatos de repetição quanto os singulares, as realidades conscientes e as inconscientes. $O$ trabalho do historiador tornou-se um ofício híbrido, marcado pelas premissas e pelas técnicas de seus investigadores vizinhos; economistas, sociólogos, antropólogos, geógrafos, psicólogos, linguistas, etc.

Já em meados do século XX, Fernand Braudel reatualizou os termos do antigo debate entre historiadores e sociólogos. À antiga provocação que a sociologia dirigia à história, colocando em dúvida seu status de ciência e exigindo dela modificações em seu método, Braudel respondeu com uma redefinição do ponto de divergência entre ambos os domínios, para o que então propôs um critério de divisão que os diferenciava segundo a atitude que tomavam em relação ao funcionamento e a dinâmica do tempo.

Não é à história que os sociólogos, finalmente e inconscientemente, querem mal, mas ao tempo da história - essa realidade que permanece violenta, mesmo se se procura ordená-la, diversificá-la, essa coação à qual o historiador jamais escapa. (BRAUDEL, 1978, p. 111) 
Dessa força imperativa do tempo, dizia o autor, os sociólogos quase sempre se evadem, seja no instante, dimensão estática da factualidade, em que a temporalidade permanece suspensa, seja nos fenômenos de repetição, que se comportam de forma quase constante no interior dos quadros da longa duração, pelo que nos dão a impressão de não pertencerem a nenhuma idade. Apontava, pois, a licitude de tal evasão como sendo a controvérsia a partir da qual se constituía o verdadeiro debate entre historiadores e sociólogos (BRAUDEL, 1978. p. 112).

Do ponto de vista de Braudel, a desconsideração das especificidades temporais dos fenômenos sociais, sua rapidez ou lentidão, sua ascensão ou queda, a renúncia, enfim, ao exame da dialética entre as diferentes durações era o que comprometia a potencialidade científica da empresa sociológica.

Por outro lado, contemporizava com seus vizinhos ao admitir que a história não se reduz à presença do ineditismo e da singularidade; "o inédito não é jamais perfeitamente inédito” (BRAUDEL, 1978, p. 96). E escolhia apostar na coexistência entre o irrepetível e o regular, apoiando-se no ponto de vista expresso por Paul Lacombe, segundo o qual os fatos seriam compostos de parte contingência e parte regularidade, parte individual e parte social.

História e sociologia se interpenetravam, portanto, em suas problemáticas, na medida em que necessitavam cruzar suas fronteiras para realizar seu trabalho de modo mais completo. Na sociologia, introduzia-se a ideia do passado em nome da repetição e da regularidade. Se o atual, para os sociólogos, cobria parte do seu trabalho, era indispensável explicar os fatos também por meio de sua recorrência no passado da humanidade. A história, por seu lado, voltava-se para o presente, a fim de ampliar sua consciência a respeito da relação entre as diferentes temporalidades. Não só buscava compreender o presente pelo passado, mas dava-se conta de que a leitura dos fatos já ocorridos está sempre condicionada por questões que são colocadas pelos historiadores no tempo atual, pelo que o entendimento sobre o passado mostrase sempre marcado pelo olhar que se lhe dirige a partir do presente.

De outra parte, no plano da longa duração, a história e a sociologia se reuniam e se confundiam. No interior desse quadro, o sociólogo necessitava assujeitar-se à rítmica dos tempos que os historiadores já elaboravam para situar os fenômenos examinados. O historiador, a seu turno, mesmo tendo compreendido a importância de se estudar a regularidade dos fenômenos, desejava ainda salvar a incerteza do movimento de massa, que demandava um olhar atento às singularidades, a tudo aquilo que tinha sua existência confinada na frágil brevidade dos instantes.

A palavra de Braudel era, portanto, conciliatória. Mais do que a mera solução de conflito, compreendia o autor que a sustentação de uma ciência do social depende de uma colaboração aberta entre os dois domínios. E projetava esta síntese desejada, afirmando que sociologia e história "eram uma só aventura do espírito, não o avesso e o direito de um estofo, mas o próprio estofo, em toda a espessura de seus fios" (BRAUDEL, 1978. p. 98). 


\title{
Foucault e os acontecimentos discursivos. A regularidade na dispersão.
}

Tendo descrito até agora um cenário onde a história, em tensa relação com a sociologia, finalmente acede à imposição de se conduzir - ao menos em certos critérios de base - segundo os moldes de uma ciência positiva, cabe-nos agora comentar a forma e o grau em que o texto foucaultiano aqui considerado teve sua produção condicionada por esse conflito que embalou o campo das ciências humanas e sociais durante o século $X X$.

Em primeiro lugar, talvez se possa dizer que, em geral, não foi o apelo direto a uma ciência de base positiva que fez tais exigências aparecerem gravadas no projeto foucaultiano, mas, de modo correlato, a indicação da necessidade de se assegurar um plano de trabalho concebido em todo seu conjunto como antimetafísico. Nessa direção, foi em nome da clareza e da distinção garantida pelo cuidado metodológico que o autor contestou as sínteses promovidas por diferentes noções que dão sustentação ao tema da continuidade - tradição, influência, desenvolvimento, evolução, mentalidade, espírito.

É preciso pôr em questão, novamente, essas sínteses acabadas, esses agrupamentos que, na maioria das vezes, são aceitos antes de qualquer exame, esses laços cuja validade é reconhecida desde o início; é preciso desalojar essas formas e essas forças obscuras pelas quais se tem o hábito de interligar os discursos dos homens; é preciso expulsá-las da sombra onde reinam. $\mathrm{E}$ ao invés de deixá-las ter valor espontaneamente, aceitar tratar apenas, por questão de cuidado com o método e em primeira instância, de uma população de acontecimentos dispersos. (FOUCAULT, 2008, p. 24)

Foucault, além disso, recusou a dimensão psicológica como estratégia de análise e buscou afastar-se de elementos que pudessem contribuir para uma análise antropologizante dos fatos, evitando assim a consideração de categorias subjetivas que viessem a contribuir para a preservação da figura humana como fonte anterior à objetividade das práticas e dos discursos. Ao invés disso, deixou-se orientar pela inclinação sociológica, voltando-se para a exterioridade dos fenômenos e dedicandose ao exame dos enunciados desde a positividade que condiciona seu aparecimento.

\begin{abstract}
Descrever um conjunto de enunciados, não em referência à interioridade de uma intenção, de um pensamento ou de um sujeito, mas segundo a dispersão de uma exterioridade; não é certamente revelar uma interpretação (...). É estabelecer o que eu chamaria, de bom grado, uma positividade. Analisar uma formação discursiva é, pois, tratar um conjunto de performances verbais, no nível dos enunciados e da forma de positividade que as caracteriza; ou, mais sucintamente, é definir o tipo de positividade de um discurso. (FOUCAULT, 2008. p. 144)
\end{abstract}

Se, por um lado, isolou em relação às categorias psicologizantes a instância do acontecimento enunciativo, negando o exame da consciência como via eleita para o exercício da análise histórica, por outro, recusou-se também a ter em conta a esfera psíquica considerada inacessível ao pensamento, evitando a apreciação da dimensão inconsciente e do exercício de interpretação que ela supõe. A esse respeito, preferiu cingir-se ao "enunciado na estreiteza e singularidade de sua situação" (FOUCAULT, 
2008, p. 31), dispondo-se a investigar a regularidade das correlações que os enunciados formam entre si.

[essas relações entre enunciados] não constituiriam, de maneira alguma, uma espécie de discurso secreto, animando, do interior, os discursos manifestos; não é, pois, uma interpretação dos fatos enunciativos que poderia trazêlos à luz, mas a análise de sua coexistência, de sua sucessão, de seu funcionamento mútuo, de sua determinação recíproca, de sua transformação independente ou correlativa. (FOUCAULT, 2008, p. 33, grifo nosso)

Das integrações que a história havia realizado à época de Braudel, Foucault acolheu o convívio entre a singularidade dos fenômenos e sua repetição, mas colocou fora de circuito o tratamento das realidades consciente e inconsciente, levando ao limite a exigência de se recusar a presença de traços especulativos na razão científica. Em sua compreensão dos fatos discursivos, assimilou, sobretudo, a exigência de se estudar os fenômenos segundo a regularidade de suas ocorrências, o que torna possível o trabalho de identificação das leis segundo as quais eles se organizam.

Mas, como se opôs à abordagem continuísta da história tradicional, que concebia o passado como uma cadeia de eventos bem conectados que nos traz à condição presente, o filósofo francês preferiu descrever a forma pela qual os elementos do discurso configuram um sistema que se ordena segundo o modo como tais elementos se afastam uns dos outros, em razão do processo de transformação ao qual estão constantemente submetidos. As leis às quais se refere são, portanto, normas que regem a regularidade pela qual os elementos do discurso se dispersam, e não por meio da qual se ligam ou se coordenam.

(...) definir um conjunto de enunciados no que ele tem de individual consistiria em descrever a dispersão desses objetos, apreender todos os interstícios que os separam, medir as distâncias que reinam entre eles - em outras palavras, formular sua lei de repartição. (FOUCAULT, 2008, p. 37.)

Com efeito, o interesse do filósofo pelo fenômeno discursivo guarda uma importante relação com a forma como os historiadores da ciência consideravam seu objeto de estudo. No capítulo O objeto da história das ciências, que integra a obra Estudos de história e de filosofia das ciências, Georges Canguilhem nos indica que falar de ciência equivale a tratar de um "discurso verificado sobre um setor delimitado da experiência” (CANGUILHEM, 2012, p. 3). Foram as articulações entre ciência e discurso que autorizaram Foucault a tomar os campos do saber como tipos particulares de agrupamentos enunciativos.

Ao mesmo tempo, posicionou-se o filósofo contra à divisão tradicional da ciência em grandes famílias de enunciados que, impondo-se ao nosso entendimento, dão forma aos diversos grupos históricos normalmente reconhecidos (medicina, economia, gramática, etc.). Nesse sentido, Foucault escolheu destacar a forma segundo a qual os enunciados constituem no tempo certos conjuntos desuniformes que se organizam não pela identidade dos enunciados de que são feitos, mas conforme condições que tornam possível a existência desses mesmos enunciados. 
Foi partindo de um sistema assim idealizado, cuja unidade supõe a dispersão de seus elementos, e cuja regularidade é governada por leis que comandam não sua síntese ou coerência interna, mas suas formas de repartição, que o autor fundou o conceito mais explorado da obra A Arqueologia do Saber: a noção de formação discursiva, inúmeras vezes apropriada por sucessores que afetaram esse conceito com diversos ajustes e adulterações, pelo que raramente esta ferramenta teórica foi reutilizada no seu valor originário - se é que de fato o foi algum dia.

\begin{abstract}
Daí a ideia de descrever essas dispersões; de pesquisar se entre esses elementos (...) não se poderia detectar uma regularidade: uma ordem em seu aparecimento sucessivo, correlações em sua simultaneidade, posições assinaláveis em um espaço comum, funcionamento recíproco, transformações ligadas e hierarquizadas. (...) No caso em que se puder descrever, entre um certo número de enunciados, semelhante sistema de dispersão, e no caso em que entre os objetos, os tipos de enunciação, os conceitos, as escolhas temáticas, se puder definir uma regularidade (uma ordem, correlações, posições e funcionamentos, transformações), diremos, por convenção, que se trata de uma formação discursiva. (FOUCAULT, 2000, p. 43)
\end{abstract}

Outrossim, a antiga divisão entre história e sociologia, que se convertera em meados do século XX num movimento de aproximação entre os campos, tornou possível o reaparecimento dos acontecimentos; únicos e singulares em sua instantaneidade, mas, desta vez, abertos também "à repetição, à transformação, à reativação" (FOUCAULT, 2008, p. 32).

No rastro da história das ciências, o filósofo se dispôs a estudar a formação de grandes unidades do discurso, a partir da descrição de diversas formas de relação entre enunciados e entre grupos de enunciados; conjuntos que teriam permanecido invisíveis em benefício de individualidades históricas antes aceitas sem qualquer questionamento. Nesse sentido, decidiu suprimir preventivamente estes agrupamentos previamente admitidos, a fim de liberar o "conjunto de todos os enunciados efetivos (quer tenham sido falados ou escritos), em sua dispersão de acontecimentos e na instância própria de cada um" (FOUCAULT, 2008, p. 30).

Nessa enorme coleção de enunciados, assim dispersos no espaço do discurso em geral, tornar-se-ia possível restituir a cada um sua singularidade de acontecimento, já que o seu exame já não mais dependia do estabelecimento de elos de coerência ou de relações fixas com outros enunciados no interior de unidades anteriormente constituídas. Mais que isso, seria possível mostrar que "a descontinuidade não é somente um desses grandes acidentes que produzem uma falha na geologia da história, mas já no simples fato do enunciado" (FOUCAULT, 2008, p. 32).

\title{
Sumarizando os resultados
}

Todas essas observações nos mostram o modo como foram retomadas no texto de A Arqueologia do Saber as discussões travadas entre sociologia e história no início do século $\mathrm{XX}$. Em posse das análises realizadas, podemos agora sumarizar o raciocínio até aqui desenvolvido com auxílio de algumas indicações pontuais. 
Inicialmente, é preciso retomar o fato de que o investimento inicial no campo da história das ciências levou Foucault a interessar-se pelo estudo do fenômeno discursivo, já que, nesse campo de investigação, a ciência foi entendida por alguns de seus predecessores - Georges Canguilhem, por exemplo - como um discurso produzido sobre uma classe especial de fenômenos. Essa correlação entre ciência e discurso justifica o aparecimento na Arqueologia da noção de acontecimento discursivo, que equivale a um evento pertinente a uma história do discurso, distinguindo-se assim de eventos relativos a outros níveis de realidade, como são os acontecimentos políticos, econômicos, sociais, etc., tematizados pelos demais campos da história.

Havíamos dito que, na França do início do século XX, a sociologia provocava a história a conduzir suas investigações em maior acordo com certo programa de ciência positiva que se queria ver imposto ao grande campo das ciências sociais. O que se pretendia era elevar o status dessas ciências, que se esforçavam para alcançar o grau de legitimidade já então atribuído às ciências da natureza.

Em consequência do projeto sociológico, duas exigências fundamentais se colocavam. De um lado, o trabalho com a regularidade dos fatos históricas, o que assegurava o estudo de suas causas e das leis segundo as quais tais ocorrências vinham a efeito; de outro, a investigação desses fenômenos considerados em sua presença no interior de um domínio objetivo, pelo que se identificavam com imposições provenientes do exterior. Essa circunscrição dos fatos estudados num plano de objetividade possuía ainda a conveniência de indicar uma correspondência entre as realidades social e material.

Tal direção de trabalho resultou ainda na proscrição da orientação psicologista, tomada como a imagem invertida da investigação conduzida no domínio das objetividades: recusava-se o exame dos processos conscientes dos agentes implicados na ocorrência dos eventos históricos, bem como a investigação dos fenômenos inconscientes que, individual ou coletivamente, atuariam primariamente sobre a atividade mental daqueles que participavam nos fatos históricos.

Apesar de os historiadores franceses ligados ao movimento dos Annales incorporarem à sua rotina de trabalho a preocupação com a regularidade dos fenômenos sociais, não perderam, todavia, o interesse pelo que tais ocorrências poderiam possuir de singular, já que, submetidas à ação do tempo, não escapavam à dimensão da finitude.

Considerados em seu conjunto, podemos dizer que os pontos de tensão entre história e sociologia antes indicados foram retomados no raciocínio desenvolvido no texto da Arqueologia do Saber, suscitando de seu autor uma tomada de posição em relação ao referido debate, do que resultaram algumas escolhas:

(i) o acontecimento discursivo foi pensado como irrupção que faz o enunciado aparecer em um espaço geral no interior do qual vai estabelecer relações diversas com outros enunciados. Face o seu caráter emergente, foi considerado desde sua diferença, no que apresenta de singular e irrecuperável. Mas os acontecimentos discursivos foram ao mesmo tempo concebidos em sua regularidade, já que o 
enunciado, uma vez dito, torna-se disponível a possíveis reativações, retomadas, reinscrições num dado campo de utilização em que passa a cumprir uma certa função. Nesse sentido, o cuidado com a singularidade do fenômeno histórico e a consideração a sua repetibilidade foram integrados à reflexão teórica sobre o discurso no projeto arqueológico foucaultiano.

(ii) a adesão a um projeto investigativo em conformidade com condições positivas de análise apareceu na consideração dos enunciados desde um campo de exterioridade cujos elementos servem à atividade enunciativa como condição de existência. Em consequência dessa escolha, foi colocado fora de circuito o tratamento das dimensões consciente e inconsciente da produção discursiva, desfazendo-se o laço pressuposto entre o dito e aquele que o diz. O sujeito do enunciado foi tomado como uma função vazia e determinada que pode ser preenchida por diferentes indivíduos.

\section{Considerações finais}

O texto de A Arqueologia do Saber traz aos analistas do discurso que atuam a partir das ciências da linguagem alguns desafios de compreensão e manejo dada a heterogeneidade dos princípios articulados em seu corpo teórico. Não é sem razão que a obra tem sido eventualmente considerada como um "um livro árido, vigorosamente personalizado" (GREGOLIN, 2006, p. 84) ou que se tenha identificado a presença de elementos que "tornam difícil a exploração do procedimento de A arqueologia do saber” (MAINGUENEAU, 2006 apud DEUSDARÁ \& RODRIGUES, 2007, p. 199).

O linguista francês Dominique Maingueneau atribui tal dificuldade ao modo como o texto da obra opera um "entrelaçamento de modos de apresentação filosóficos e procedimentos clássicos nas ciências sociais" (MAINGUENEAU, 2006 apud DEUSDARÁ \& RODRIGUES, 2007, p. 199). Apesar do enlace entre os dois grandes domínios, as tentativas de sua leitura são predominantemente realizadas a partir da filosofia - o que não quer dizer que tais resultados facilmente convirjam. Comparese, por exemplo, o comentário de Dominique Lecourt (1996), que procura articular a obra de Foucault com o projeto marxista, operando uma espécie de tradução de sua linguagem para torná-la palatável aos althusserianos da segunda geração; com a leitura de Jürgen Habermas, que atribui à "recepção de Nietzsche - sintetizada na introdução à Arqueologia do Saber e no ensaio sobre 'Nietzsche, a genealogia e a história' - o conceito de uma historiografia positivista e erudita que se apresenta como anticiência" (HABERMAS, 2000, p. 348-349).

Fato é que as relações constitutivas existentes entre o texto dessa obra e os trabalhos fundantes do campo das ciências sociais têm recebido menor atenção, o que talvez se deva a uma lógica disciplinarizante que prescreve a análise de um texto segundo seu campo de pertencimento. No caso foucaultiano, esse procedimento inevitavelmente fracassa. Pode-se mesmo dizer que, em seu trabalho, opera-se uma estratégia de pesquisa que mais se aproxima de uma orientação pós-disciplinar. $O$

Revista História em Reflexão, Vol. 15, N. 29 | jan. a jun. de 2021 
autor emprega seu esforço, articulando princípios de origens diversas sem estabelecer compromisso com os campos a partir dos quais os toma de empréstimo. Em certa medida, o próprio projeto de uma descrição dos acontecimentos discursivos que Foucault apresenta em sua obra serve de apoio ao modo como o autor se situa em relação aos diferentes domínios com os quais se relaciona, já que as unidades do discurso, do ponto de vista arqueológico, não coincidem com as grandes famílias de enunciados que a história nos indica como esferas circunscritas de conhecimento.

Supondo que o texto de A Arqueologia do Saber é significativamente formado pelas relações que estabelece com textos anteriores pertinentes ao domínio das ciências sociais, exploramos neste trabalho o espaço intertextual no interior do qual a obra funciona, de modo a evidenciar sua relação constitutiva com as polêmicas estabelecidas entre história e sociologia na primeira metade do séculoXX. Identificamos, na orientação de trabalho adotada por Foucault, a presença de um raciocínio teórico integrado que os novos historiadores já praticavam, porquanto estavam atentos tanto à singularidade dos fatos históricos, face sua suscetibilidade à força imperativa do tempo, como à sua recorrência, sua quase constância nos quadros da longa duração. Por outro lado, verificamos a recusa da dimensão psicológica como estratégia de análise, o que seguia sendo interesse entre os historiadores dos Annales, em benefício de uma posição sociológica que prescreve o estudo dos fenômenos segundo sua presença manifesta em um campo de exterioridade.

Com as indicações até aqui relacionadas, sugerimos um caminho de investigação pelo qual avançamos os primeiros passos com esta oportunidade. Demonstramos que o célebre texto de Foucault pode ser pensado não apenas em sua qualidade de texto fundacional, ponto de partida das reflexões e dos trabalhos de uma certa tendência da análise do discurso; mas igualmente a partir de seu estatuto de texto-comentário, na medida em que seu corpo textual reelabora, retoma, refraseia textos anteriores que, no campo das ciências sociais, ocuparam também um lugar fundador.

Nossa aposta é pelo fato de que, conhecendo os problemas e as discussões que mobilizaram o interesse dessa obra, os investigadores dedicados à análise do discurso estarão em melhores condições não apenas de fazer a sua leitura, mas de realizar um manejo direto e interventivo do texto, sem estarem, portanto, reduzidos à condição de meros operadores das apropriações teóricas que se fizeram canônicas para a tendência francesa da análise do discurso.

\section{Referências}

BRAUDEL, Fernand. Escritos sobre a História. São Paulo: Perspectiva, 1978.

CANGUILHEM, Georges. Estudos de história e de filosofia das ciências: concernentes aos vivos e à vida. Rio de Janeiro: Forense Universitária, 2012. 
DURKHEIM, Émile et al. "Débat sur l'explication en histoire et en sociologie". Disponível em: <http://classiques.uqac.ca/classiques/Durkheim_emile/textes_1/ textes_1_09/histoire_socio.html>. Acesso em: 20 nov. 2019.

FOUCAULT, Michel. A arqueologia do saber. 6 ${ }^{a}$ ed. Rio de Janeiro: Forense Universitária, 2000.

GREGOLIN, Maria do Rosário. Foucault e Pêcheux na análise do discurso diálogos \& duelos. 2a ed. São Carlos: Editora Claraluz, 2006.

HABERMAS, Jürgen. 0 discurso filosófico da modernidade. São Paulo: Martins Fontes, 2000.

$\mathrm{KOCH}$, Ingedore Villaça. Introdução à linguística textual. $2^{\mathrm{a}}$ ed. São Paulo: Contexto, 2017.

LECOURT, Dominique. A arqueologia e o saber. In: 0 homem e o discurso: a arqueologia de michel foucault. $2^{\mathrm{a}}$ ed. Rio de Janeiro: Tempo Brasileiro, 1996.

MAINGUENEAU, Dominique. Cenas da enunciação. Curitiba: Criar, 2006. Resenha de: DEUSDARÁ, Bruno \& RODRIGUES, Isabel Cristina. Percursos da enunciação em análise do discurso. Matraga, v. 14, n. 20, 198-202, 2007.

SIMIAND, François. Método histórico y ciencia social (Presentación y traducción de Antonio F. Vallejos). Empiria. Revista de metodología de ciencias sociales, v. $0, n$. 6, p. 163-202, 2003.

Recebido em dezembro de 2019.

Aprovado para publicação em novembro de 2020. 